\title{
Pontomesencephalic Atrophy and Postural Instability in Wilson Disease
}

\author{
(D). Kalita, (D) S. Naik, (D)S.K. Bhoi, (D) U.K Misra, (D)A. Ranjan, and (D) S. Kumar
}

\begin{abstract}
BACKGROUND AND PURPOSE: The MR Parkinsonism index helps in differentiating progressive supranuclear palsy from Parkinson disease and multisystem atrophy. Pontomesencephalic involvement is common in neurologic Wilson disease, but there is no prior study evaluating the MR Parkinsonism index and its indices in Wilson disease. We report the MR Parkinsonism index and its indices in Wilson disease and correlate these changes with clinical severity and postural reflex.
\end{abstract}

MATERIALS AND METHODS: Thirteen individuals with neurologic Wilson disease were included, and their clinical details, including neurologic severity, postural reflex abnormality, and location of signal changes on MR imaging, were noted. The 3D BRAVO T1 sequence was used for measurement of the MR Parkinsonism index and its indices. The MR Parkinsonism index and its indices were also obtained in 6 age- and sex-matched controls. The morphometric parameters in Wilson disease were compared with those in with healthy controls and among the patients with and without abnormal postural reflex.

RESULTS: The midbrain area was reduced in patients with Wilson disease compared with controls (112.08 \pm 27.94 versus $171.95 \pm 23.66$ $\left.\mathrm{mm}^{2}, P=.002\right)$. The patients with an abnormal postural reflex had an increased MR Parkinsonism index and pons-to-midbrain ratio compared with controls, whereas these parameters were equivalent in patients with normal postural reflex and controls. The patients with abnormal postural reflex had more severe illness, evidenced by higher Burke-Fahn-Marsden scores (51.0 \pm 32.27 versus 13.75 $\pm 12.37, P=.04)$ and neurologic severity grades $(2.57 \pm 0.53$ versus $1.67 \pm 0.82, P=.04)$.

CONCLUSIONS: An increase in the MR Parkinsonism index in Wilson disease is mainly due to midbrain atrophy and it correlates with neurologic severity and abnormal postural reflex.

ABBREVIATIONS: MCP = middle cerebellar peduncle; MRPI = MR Parkinsonism index; PD = Parkinson disease; PSP = progressive supranuclear palsy; $\mathrm{SCP}=$ superior cerebellar peduncle; WD = Wilson disease

W ilson disease (WD) is an autosomal recessive disorder of copper metabolism due to $A T P 7 B$ mutation on chromosome $13 \mathrm{q} 14.3 .{ }^{1}$ It is a rare disease with a world wide prevalence of $1-2 / 100,000$ population. ${ }^{2}$ Neurologic manifestation in WD usually occurs in the second decade and is characterized by cognitive decline, drooling, and varying severity of extrapyramidal and pyramidal symptoms and signs. ${ }^{3-5}$ The characteristic cranial MR

Received September 14, 2016; accepted after revision February 21, 2017. From the Departments of Neurology (J.K., S.K.B., U.K.M., A.R.) and Radiology (S.N. S.K.), Sanjay Gandhi Post Graduate Institute of Medical Sciences, Lucknow, India.

This study was approved by Institutional Ethics Committee, Sanjay Gandhi Post Graduate of Medical Sciences, Lucknow India.

Please address correspondence to J. Kalita, MD, DM, Department of Neurology, Sanjay Gandhi Post Graduate Institute of Medical Sciences, Raebareily Rd, Lucknow 226014, Uttar Pradesh, India; e-mail; jayanteek@yahoo.com, jkalita@sgpgi.ac.in

DIndicates article with supplemental on-line video.

http://dx.doi.org/10.3174/ajnr.A5207 imaging abnormalities in WD are corpus striatal involvement and the "giant Panda sign," which are reported in $14.3 \%-71.5 \%$ of patients. ${ }^{6-8}$ Involvement of the pons and midbrain may lead to an abnormal postural reflex in WD, which may increase the neurologic disability. Recently, the MR Parkinsonism index (MRPI) has been reported to correctly differentiate progressive supranuclear palsy (PSP) from Parkinson disease (PD) and multisystem atrophy. ${ }^{9-11}$ These studies did not correlate the MRPI with postural reflexes. The loss of neurons in the mesencephalic locomotor region and pedunculopontine region has been reported in postmortem studies on PD and PSP. ${ }^{12,13}$ Stroke in these areas has been reported with freezing and impaired gait initiation. ${ }^{14-16}$

Abnormal postural reflex renders an individual prone to falls, leading to fractures and head injury. The MRPI may be a radiologic marker of abnormal postural reflex but this has not been studied. In neurologic WD, involvement of the midbrain and pons on MR imaging has been reported in up to $66 \%$ of patients. ${ }^{4,8}$ There is no study evaluating postural reflex and MRPI in 

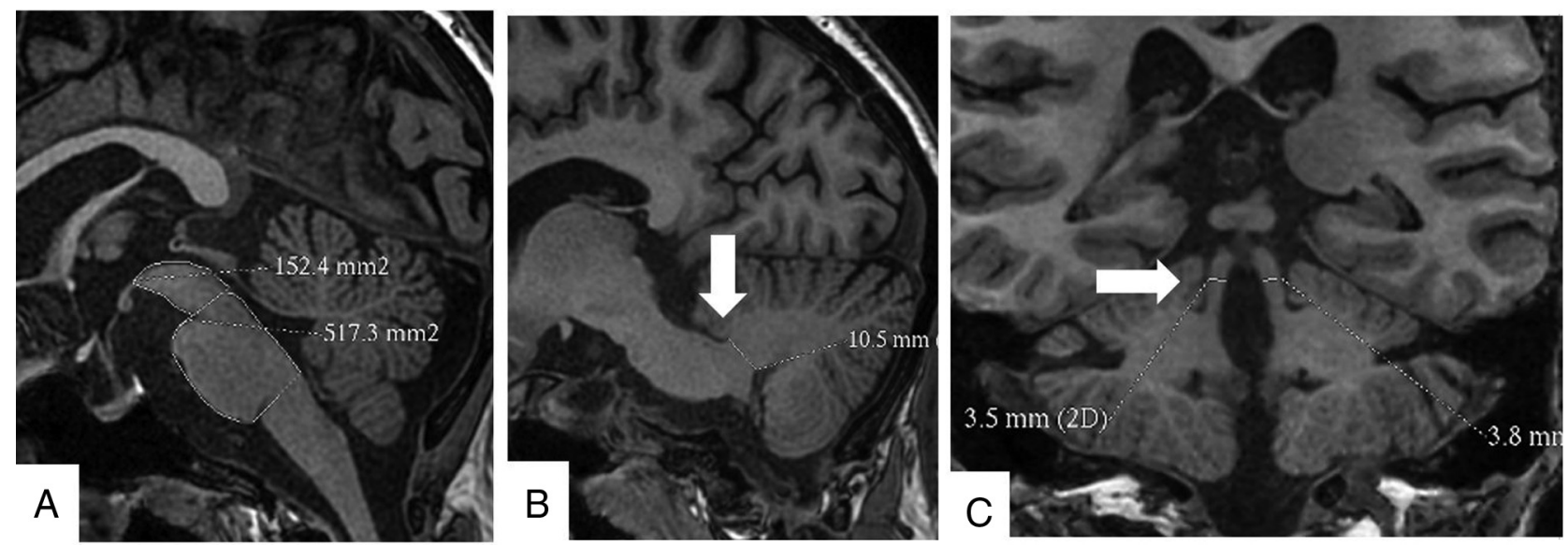

FIG 1. Cranial MR imaging in the BRAVO 3D sequence showing the protocol of measurement of the midbrain and pons areas ( $A$ ), width of the middle cerebellar peduncle (B), and width of the superior cerebellar peduncle (C).

patients with neurologic WD, to our knowledge. In this communication, we report MRPI parameters in patients with neurologic $\mathrm{WD}$ and correlate these with postural reflex and disease severity.

\section{MATERIALS AND METHODS}

Patients with WD having neurologic manifestations were prospectively included. The diagnosis of WD was based on characteristic clinical features, a Kayser-Fleischer ring on slit lamp examination, serum ceruloplasmin levels $(<20 \mathrm{mg} / \mathrm{dL}$ ), and 24-hour urinary copper excretion $(>40 \mu \mathrm{g}) .^{17,18}$ The study was approved by the ethics committee of the institution. A detailed clinical history, including duration of illness, cognitive decline, drooling, seizures, abnormal movements, jaundice, and skeletal abnormality, was noted. A pedigree chart was prepared for each index patient. The neurologic severity of WD was grades I-III based on 5 signs (tremor, dysarthria, ataxia, rigidity/bradykinesia, and chorea/dystonia). ${ }^{19}$ The severity of dystonia was assessed by the Burke-Fahn-Marsden score. ${ }^{20}$ Patients were examined for nystagmus, horizontal and vertical gaze, and saccadic and pursuit eye movements. Postural reflex was assessed by the pull test. The examiner stood behind the patient, and the patient was instructed to maintain the same erect, stable posture when subjected to a sudden backward pull on their shoulders. The pull test result was considered abnormal if the patient went $>2$ steps backward or lost balance. $^{21}$

\section{Investigations}

Routine laboratory tests, including clotting parameters, were assessed for any abnormalities. The serum and urinary copper levels were assessed by an atomic absorption spectrophotometer. The serum-free copper level was calculated by subtracting 3 times the serum ceruloplasmin level from the total serum copper level (microgram/deciliter). ${ }^{17,22}$ A sonographic abdomen examination was performed.

Cranial MR Imaging. Cranial MR imaging was performed by using a 3T Signa scanner (GE Healthcare, Milwaukee, Wisconsin). We obtained the following sequences: T1 (TR, $1254 \mathrm{~ms}$; TE, $11.6 \mathrm{~ms}$ ), T2 (TR, $5600 \mathrm{~ms}$; TE, $95.5 \mathrm{~ms}$ ), fast fluid-attenuated inversion recovery (TI, $2200 \mathrm{~ms}$; TR, $8802 \mathrm{~ms}$; TE, $85.4 \mathrm{~ms}$ ), and DWI (TR, $5600 \mathrm{~ms}$; TE, $72.4 \mathrm{~ms}$, at $2 \mathrm{~b}$-values of 0 and $1000 \mathrm{~s} / \mathrm{mm}^{2}$ ). The isotropic diffusion-weighted images were reviewed. All images were 5 -mm-thick with an intersection gap of $0.5 \mathrm{~mm}$. Matrix size was $256 \times 256$ with NEX $=1$. Abnormal signal, extent, and location were noted.

The T1-weighted 3D BRAVO sequence (GE Healthcare) was performed in 13 patients and 6 controls. We used the following parameters: TR/TE, $8.4 / 3.3 \mathrm{~ms}$; TI, $400 \mathrm{~ms}$; flip angle, $13^{\circ}$; FOV, $240 \times 240$ $\mathrm{mm}^{2}$; matrix, $288 \times 288$; and section thickness, $1-\mathrm{mm}$ without intersection gap. The acquisition time was 4.08 minutes.

The midbrain and pons areas were measured on the midsagittal 3D BRAVO sequence. A line passing through the superior pontine notch and the inferior edge of the quadrigeminal plate was taken as the demarcating line between midbrain and pons. A second line parallel to the first line passing through the inferior pontine notch was taken as the lower margin of the pons. The midbrain area was traced around the edges of the midbrain tegmentum above the first line. The tectum of the midbrain was not included. The pons area was included craniocaudally between the 2 above-mentioned lines and along the anterior and posterior margins of the pons anteroposteriorly. The width of the middle cerebellar peduncle (MCP) was measured on parasagittal views of the 3D BRAVO sequence. Left and right MCPs were identified on parasagittal views on which the MCP was best exposed between the pons and the cerebellum. The distance between the superior and inferior borders of the MCP was measured, as delineated by the peripeduncular CSF spaces of the pontocerebellar cisterns. Each MCP width (left and right) was measured, and a mean value for the $2 \mathrm{MCPs}$ was calculated. The superior cerebellar peduncles (SCPs) were measured on the coronal views of the 3D BRAVO sequence. In the coronal view, images were inspected in the anteroposterior direction parallel to the axis of the brain stem to identify the SCP. The linear distance between the medial and lateral borders of the superior cerebellar peduncle was measured at the middle of their extension, and an average of the 2 SCPs was calculated. The ratios of pons-to-midbrain area and MCP-to-SCP width $(\mathrm{MCP} / \mathrm{SCP})$ were also used, and the MRPI was calculated by Pons Area / Midbrain Area $\times$ MCP width/SCP width (Fig 1). ${ }^{11}$

\section{Statistical Analysis}

The MRPI and its different indices in patients were compared with 6 age- $(23.15 \pm 8.72$ versus $20.50 \pm 6.60, P=.54)$ and sex- 

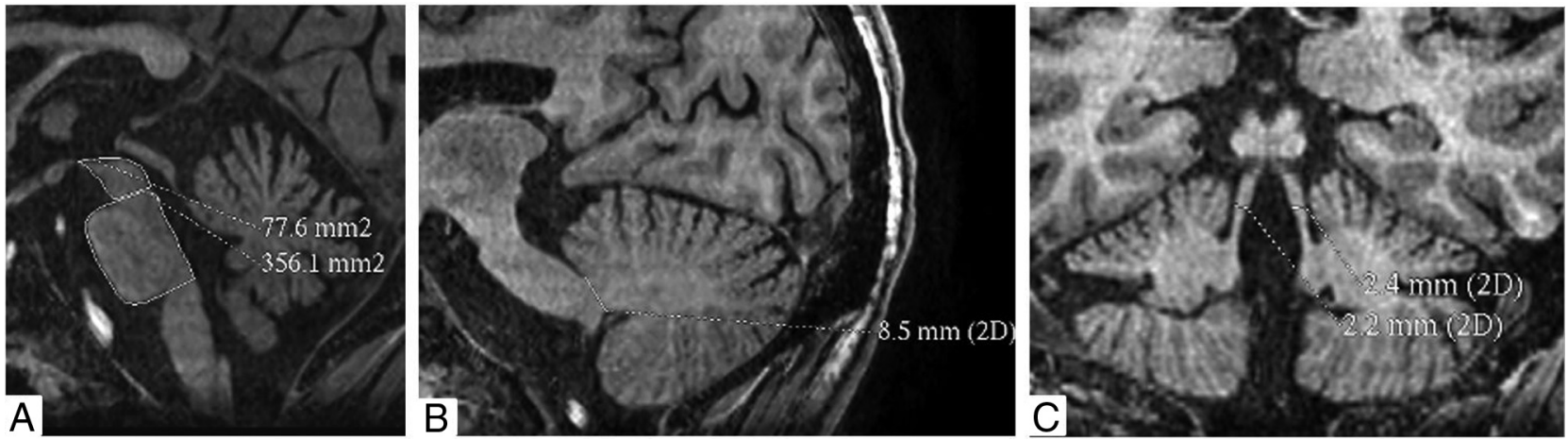

FIG 2. Cranial MR imaging of a 31-year-old woman with Wilson disease shows increased pons-to-midbrain areas $\left(4.59 \mathrm{~mm}^{2}\right)(A)$, reduced width of the middle cerebellar peduncle $(8 \mathrm{~mm})(B)$, and a reduced width of superior cerebellar peduncle $(2.3 \mathrm{~mm})(C)$. Her MR Parkinsonism index was increased (16.9). She had impaired postural reflex.

\begin{tabular}{|c|c|c|c|c|}
\hline $\begin{array}{c}\text { Serial } \\
\text { No. }\end{array}$ & Parameters & $\begin{array}{l}\text { Wilson Disease } \\
\qquad(n=13)\end{array}$ & $\begin{array}{c}\text { Controls } \\
(n=6)\end{array}$ & $P$ Value \\
\hline 1 & Age (mean) (yr) & $23.15 \pm 8.72$ & $20.50 \pm 6.60$ & .54 \\
\hline 2 & Female/male & $5: 8$ & $2: 4$ & 1.00 \\
\hline 3 & $\mathrm{MB}$ area (mean) $\left(\mathrm{mm}^{2}\right)$ & $112.08 \pm 27.94$ & $171.95 \pm 23.66$ & .002 \\
\hline 4 & Pons area (mean) $\left(\mathrm{mm}^{2}\right)$ & $402.45 \pm 45.47$ & $469.27 \pm 45.62$ & .02 \\
\hline 5 & Right MCP (mean) (mm) & $8.68 \pm 0.76$ & $9.78 \pm 1.01$ & .04 \\
\hline 6 & Left MCP (mean) (mm) & $8.72 \pm 0.93$ & $9.73 \pm 1.15$ & .07 \\
\hline 7 & Mean MCP (mean) (mm) & $8.70 \pm 0.81$ & $9.76 \pm 1.12$ & .06 \\
\hline 8 & Right SCP (mean) (mm) & $2.90 \pm 0.53$ & $3.65 \pm 0.58$ & .03 \\
\hline 9 & Left SCP (mean) (mm) & $3.12 \pm 0.49$ & $3.73 \pm 0.55$ & .06 \\
\hline 10 & Mean SCP (mean) (mm) & $3.01 \pm 0.50$ & $3.71 \pm 0.57$ & .03 \\
\hline 11 & Pons area/MB area (mean) (mm) & $3.75 \pm 0.78$ & $2.75 \pm 0.20$ & .004 \\
\hline 12 & $\mathrm{MCP} / \mathrm{SCP}$ (mean) (mm) & $2.96 \pm 0.56$ & $2.67 \pm 0.44$ & .22 \\
\hline 13 & MR parkinsonism index ${ }^{a}$ & $11.01 \pm 2.99$ & $7.31 \pm 1.20$ & .002 \\
\hline
\end{tabular}

Note:-MB indicates midbrain.

${ }^{\text {a }}$ MR Parkinsonism index $=($ Pons area $/ \mathrm{MB}$ area $) \times(\mathrm{MCP}$ width $/ \mathrm{SCP}$ width $)$.

cle power was normal in all, though tendon reflexes were brisk in 10 patients. Seven patients had abnormal postural reflex on the pull test: Four had $>2$ steps backward-stepping and 3 lost their balance (On-line Video 1). Nine patients had slow pursuit and broken saccadic eye movements in both horizontal and vertical gazes.

\section{MR Imaging Findings}

Cranial MR imaging findings were abnormal in all and revealed the following involvement: putaminal in 11; globus pallidus in 6; caudate in 6; thalamus, midbrain, and pons in 8 each; subcortical white matter in 2 ; frontal cortex in 1 ; middle cerebellar peduncle in 2 ; and cer-

(M/F, $8: 5$ versus $4: 2 ; P=1.00)$ matched healthy controls by using the Mann-Whitney $U$ test. The MRPI and its parameters in WD were also compared with clinical, MR imaging findings; the Burke-Fahn-Marsden score; and the severity of WD by using various parametric and nonparametric tests. The MRPI and its indices were also compared between controls and patients with WD with and without an abnormal postural reflex by 1-way ANOVA with the Tukey multiple comparison test. The statistical analysis was performed by using SPSS, Version 16, software (IBM, Armonk, New York), and graphs were prepared with GraphPad Prism 5 software (GraphPad Software, San Diego, California). The variable was considered significant if the 2-tailed $P$ value was $<.05$.

\section{RESULTS}

Thirteen patients with WD with neurologic manifestations were included whose median age was 23 years (range, $12-40$ years); 5 were females. The median duration of illness was 18 months (range, 3-84 months). Only 1 patient had a history of jaundice. All patients had varying types and severity of movement disorders, which included dystonia in all, tremor in 10, choreoathetosis in 1 , and myoclonus in 1 patient. Seven patients had drooling. The Burke-Fahn-Marsden score ranged between 2 and 84 (median, 24). Three patients had grade I severity, and the remaining patients had grades II and III. Mus- ebellum in 1 patient. These lesions were hyperintense in T2 and FLAIR, and diffusion restriction in a frontal lesion was found in 1 patient.

\section{Morphometric Parameters on MR Imaging}

The areas of the pons $(P=.02)$ and midbrain $(P=.002)$ and the width of the SCP $(P=.03)$ were reduced in patients with WD compared with the controls. The midbrain was more atrophied compared with the pons; this finding was evident by an increase in the ratio of the pons to the midbrain area in patients compared with controls $(P=.004)$. The ratio of MCP to SCP width, however, was not different between patients and controls $(P=.22)$. The MRPI was higher in patients with WD compared with controls $(11.01 \pm 2.99$ versus $7.31 \pm 1.20, P=.002$; Fig 2$)$. The details are presented in the Table.

\section{Clinical Correlation}

The postural reflex was abnormal in 7 and normal in 6 patients; both of these groups had reduced midbrain areas compared with controls $(P<.001)$. The patients with abnormal postural reflex had significant reduction in the pons area $(P<.01)$, MCP width $(P<.05)$, and SCP width $(P<.05)$ compared with controls. These 3 parameters, however, were not significantly different between controls and patients with WD with normal postural re- 


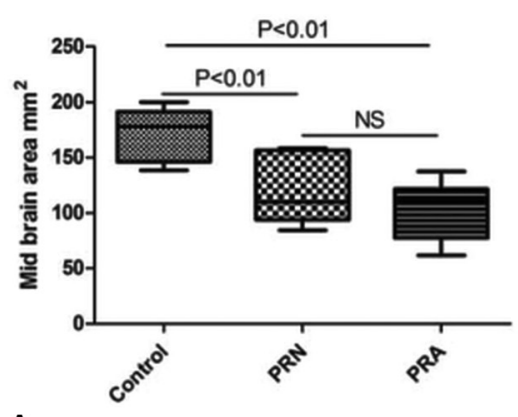

A
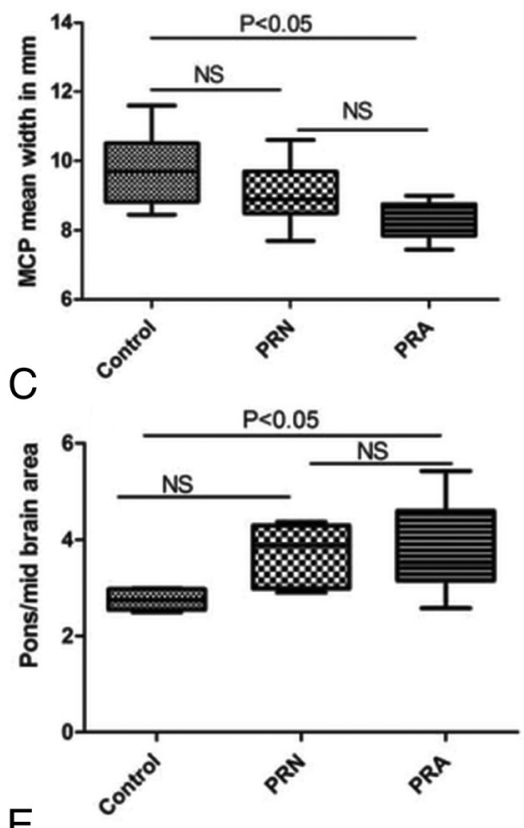

E

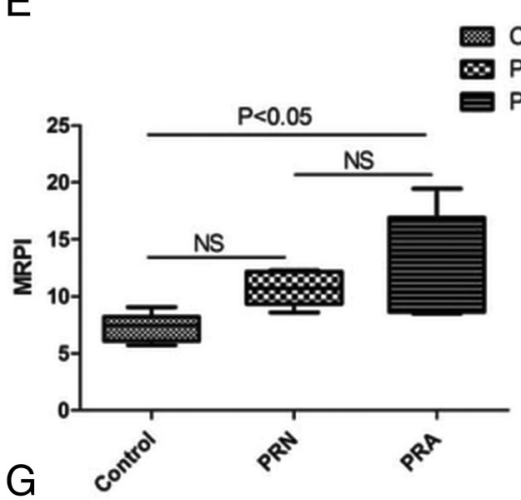

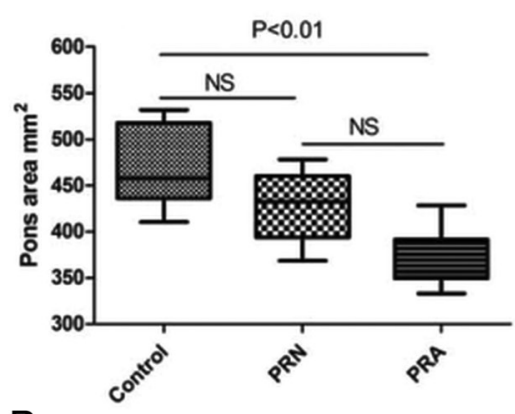

B
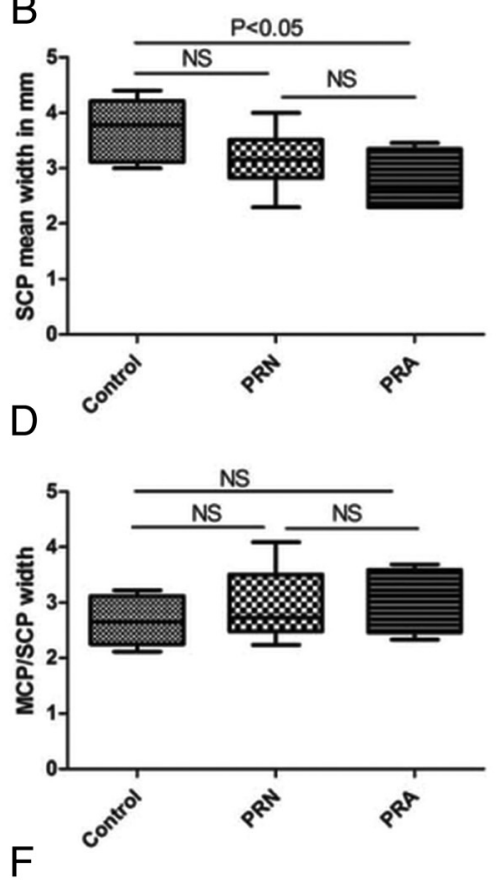

postural reflex had more severe illness, evidenced by higher Burke-Fahn-Marsden scores (51.0 \pm 32.27 versus $13.75 \pm$ $12.37, P=.04)$ and higher grades of neurologic severity $(2.57 \pm 0.53$ versus $1.67 \pm 0.82, P=.04)$.

\section{DISCUSSION}

This study revealed an increase in the MRPI and pons-to-midbrain ratio in patients with WD compared with controls. These changes were more marked in patients with abnormal postural reflex, and abnormal postural reflex correlated with neurologic severity. This is the first study reporting morphometric evaluation of brain stem structures and MRPI in WD and correlating these parameters with clinical severity and postural reflex. During the past 20 years, a number of MR imaging features and morphometric parameters have been evaluated to differentiate PSP and multisystem atrophy from PD. ${ }^{9-11}$ The overlapping clinical features sometime cause difficulty in differentiating PSP from PD and multisystem atrophy-Parkinson. In a study on 45 patients with clinically unclassifiable parkinsonism, MRPI $\geq$ 13.55 predicted PSP at 3-year follow-up with $100 \%$ sensitivity, $90.3 \%$ specificity, and $92.9 \%$ accuracy. ${ }^{11}$ The patients with MRPI $\geq 13.55$ had higher Unified Parkinson's Disease Rating Scale scores and more frequent falls compared with those with MRPI < 13.55. In our study, none of the controls had MRPI $>9$, but 10 of 13 patients with WD had MRPI $\geq 9$. All our patients were children or young adults, and none were older than 40 years of age. We therefore used normal age- and sex-matched controls. The ratio of MCP-to-SCP width was not significantly different in the patients with WD compared with controls. In PSP, the MCP-to-SCP ratio was increased due to greater reduction of the SCP width. Conventional MR imaging did not reveal any signal changes in PSP, multisys-

FIG 3. Error bar diagram shows the MR Parkinsonism index and its indices in patients with disease with postural reflex abnormality compared with patients with WD with normal postural reflex (PRN) and healthy controls. The midbrain area was reduced in patients with WD with and without postural reflex abnormality (PRA), but MRPI and pons-to-midbrain areas were increased and the width of the superior and middle cerebellar peduncles was decreased in patients with WD with postural reflex abnormality but not patients with normal postural reflex compared with controls.

flexes. The pons-to-midbrain ratio $(P<.05)$ and MRPI $(P<.05)$ were significantly increased in patients with WD with abnormal postural reflexes compared with those with normal postural reflexes and healthy controls. The details are presented in Fig 3.

The presence of abnormal signal changes in the midbrain and pons was not related to the midbrain area $(105.83 \pm 25.41$ versus $\left.119.38 \pm 31.30 \mathrm{~mm}^{2}, P=.77\right)$ and pons area $(380.57 \pm 39.65$ versus $427.97 \pm 40.29 \mathrm{~mm}^{2}, P=.06$ ). The patients with abnormal tem atrophy, and $\mathrm{PD}$; whereas in $\mathrm{WD}$, midbrain involvement occurred in $32.4 \%-49 \%$ of patients. ${ }^{4,8,23}$

The involvement of the pons, cerebellum, and cerebellar peduncles, however, is rare in WD. The signal changes in the midbrain and pons in our patients, however, were not related to the midbrain and pons areas, respectively. This finding suggests that the reduction of the midbrain and pons areas may be due to chronic degeneration or apoptosis of the neurons of the midbrain 
locomotor region and pedunculopontine neurons. Dopaminergic and other aminergic neurons of the brain stem are metabolically active; therefore, they are vulnerable to oxidative stress. Serum-free copper levels are increased in WD and can cross the blood-brain barrier and may result in oxidative injury. In a study on neurologic WD, serum antioxidants (glutathione and total antioxidant capacity) were reduced and the oxidative marker (malonodialdehyde) and tumor necrosis factor- $\alpha$ were increased. These parameters were related to serum-free copper and urinary excretion of copper. ${ }^{22}$ In another study, an increase in death signal (tumor necrosis factor $\alpha$, interleukin 8, malonodialdehyde) and reduction in survival signal (glutathione and X-link inhibitors of apoptosis protein) have been reported. ${ }^{23}$

Posture is a reflex and involves involuntary contraction of antigravity muscles to maintain an erect posture. Human locomotion is presumed to have supraspinal control, whereas animal locomotion is mostly spinal. The pedunculopontine nuclei are located in the pontomesencephalic tegmentum and are thought to be the anatomic substrate of human locomotion. Pedunculopontine nuclei are reciprocally connected to the limbic system, globus pallidus, subthalamic nuclei, substantia nigra, and brain stem reticular formation. The rhythmic activity of pedunculopontine nuclei is under cerebellar control. Reduction in the number of pedunculopontine neurons may result in dopamine-resistant extrapyramidal syndrome, including freezing, postural instability, and sleep disturbance. ${ }^{24}$ The dystonia in WD is also resistant to dopaminergic drugs. ${ }^{25}$

The present study is limited by the small number of patients. WD is a rare inherited metabolic disease. Many patients with WD die in the first decade due to liver failure, and only a few survive to develop neurologic manifestations. The results of our study are helpful in understanding the basis of postural instability in WD. Increased MRPI and midbrain-to-pons ratio may be the radiologic markers of postural instability in WD but need confirmation in a larger study. The improvement in postural reflex following chelating treatment may correspond with improvement in MRPI and midbrain-to-pons ratio, which may be explored in a future longitudinal study.

\section{CONCLUSIONS}

An increase in MRPI in WD is mainly due to midbrain atrophy, and it correlates with abnormal postural reflex and neurologic severity.

\section{ACKNOWLEDGMENTS}

We thank Mr Rakesh Kumar Nigam and Mr Shakti Kumar for the secretarial help.

\section{REFERENCES}

1. Bull PC, Thomas GR, Rommens JM, et al. The Wilson disease gene is a putative copper transporting P-type ATPase similar to the Menkes gene. Nat Genet 1993;5:327-37 CrossRef Medline

2. Jankovic J. Movement disorder. In: Daroff RB, Fenichel GM, Jankovic J, et al, eds. Bradley's Neurology in Clinical Practice. 6th ed. Philadelphia: Elseiver/Saunders; 2012:1762-1801

3. Kalita J, Kumar V, Ranjan A, et al. Role of oxidative stress in the worsening of neurologic Wilson disease following chelating therapy. Neuromolecular Med 2015;17:364-72 CrossRef Medline

4. Sinha S, Taly AB, Ravishankar S, et al. Wilson's disease: cranial MRI observations and clinical correlation. Neuroradiology 2006;48: 613-21 CrossRef Medline

5. Broussolle E, Trocello JM, Woimant F, et al. Samuel Alexander Kinnier Wilson: Wilson's disease, Queen Square and neurology. Rev Neurol (Paris) 2013;169:927-35 CrossRef Medline

6. Singh S, Behari M. Wilson's disease. J Assoc Physicians India 2003;51: 183-90 Medline

7. Prashanth LK, Sinha S, Taly AB, et al. Do MRI features distinguish Wilson's disease from other early onset extrapyramidal disorders? An analysis of 100 cases. Mov Disord 2010;25:672-78 CrossRef Medline

8. Ranjan A, Kalita J, Kumar S, et al. A study of MRI changes in Wilson disease and its correlation with clinical features and outcome. Clin Neurol Neurosurg 2015;138:31-36 CrossRef Medline

9. Kim YH, Ma HI, Kim YJ. Utility of the midbrain tegmentum diameter in the differential diagnosis of progressive supranuclear palsy from idiopathic Parkinson's disease. J Clin Neurol 2015;11:268-74 CrossRef Medline

10. Quattrone A, Nicoletti G, Messina D, et al. MR imaging index for differentiation of progressive supranuclear palsy from Parkinson disease and the Parkinson variant of multiple system atrophy. $R a-$ diology 2008;246:214-21 CrossRef Medline

11. Morelli M, Arabia G, Novellino F, et al. MRI measurements predict PSP in unclassifiable parkinsonisms: a cohort study. Neurology 2011;77:1042-47 CrossRef Medline

12. Zweig RM, Jankel WR, Hedreen JC, et al. The pedunculopontine nucleus in Parkinson's disease. Ann Neurol 1989;26:41-46 CrossRef Medline

13. Pahapill PA, Lozano AM. The pedunculopontine nucleus and Parkinson's disease. Brain 2000;123(pt 9):1767-83 CrossRef Medline

14. Kuo SH, Kenney C, Jankovic J. Bilateral pedunculopontine nuclei strokes presenting as freezing of gait. Mov Disord 2008;23:616-19 CrossRef Medline

15. Masdeu JC, Alampur U, Cavaliere R, et al. Astasia and gait failure with damage of the pontomesencephalic locomotor region. Ann Neurol 1994;35:619-21 CrossRef Medline

16. Hathout GM, Bhidayasiri R. Midbrain ataxia: an introduction to the mesencephalic locomotor region and the pedunculopontine nucleus. AJR Am J Roentgenol 2005;184:953-56 CrossRef Medline

17. Kalita J, Kumar V, Misra UK, et al. A study of oxidative stress, cytokines and glutamate in Wilson disease and their asymptomatic siblings. J Neuroimmunol 2014;274:141-48 CrossRef Medline

18. Roberts EA, Schilsky ML; American Association for Study of Liver Disease (AASLD). Diagnosis and treatment of Wilson disease: an update. Hepatology 2008;47:2089-111 CrossRef Medline

19. Grimm G, Prayer L, Oder W, et al. Comparison of functional and structural brain disturbances in Wilson's disease. Neurology 1991; 41:272-76 CrossRef Medline

20. Krystkowiak P, du Montcel ST, Vercueil L, et al; SPIDY Group. Reliability of the Burke-Fahn-Marsden scale in a multicenter trial for dystonia. Mov Disord 2007;22:685-89 CrossRef Medline

21. Fahn S, Elton RL, members of the UPDRS Development Committee. The Unified Parkinson's Disease Rating Scale. In: Fahn S, Marsden CD, Calne DB, et al, eds. Recent Developments in Parkinson's Disease. Vol. 2. New York: Raven Press; 1986:153-63, 293-304

22. Das SK, Ray K. Wilson's disease: an update. Nat Clin Pract Neurol 2006;2:482-93 CrossRef Medline

23. Kalita J, Kumar V, Misra UK. A study on apoptosis and anti-apoptotic status in Wilson disease. Mol Neurobiol 2016;53:6659-67 CrossRef Medline

24. Bartels AL, Leenders KL. Brain imaging in patients with freezing of gait. Mov Disord 2008;23(suppl 2):S461-67 CrossRef Medline

25. Kalita J, Ranjan A, Misra UK. Oromandibular dystonia in Wilson disease. Movement Disorders Clinical Practice 2015;2:253-59 CrossRef 